\title{
Could Meeting Familial, Psychosocial and Cultural Expectations under the Aegis of Palliative Care Result in a Slippery Slope to Hastening of Death?
}

\author{
Lalit Krishna*
}

Department of Palliative Medicine, National Cancer Centre, Singapore

Received: December 10, 2013; Accepted: December 28, 2013; Published: January 07, 2014

“Corresponding author: Lalit Krishna, Department of Palliative Medicine, National Cancer Centre, 11 Hospital Drive, Singapore 169610, Tel: +65 64368461; Fax:+65 6220 7490; Email: lalit.krishna@nccs.com.sg

\begin{abstract}
Palliative care utilises inclusive and reflexive practices in order to meet its pivotal goal of holistic care provision. This practice has been seized upon by detractors who posit that such working practices in attempting to accommodate and respond appropriately to the demands and considerations of cultural, religious, psychosocial and local beliefs will succumb to increasingly aberrant practices. These repeated and increasing overt breaches are thought to represent a slippery slope to unacceptable practices. Using the example of Continuous Deep Sedation within the context of end of life care, this paper will investigate the possibility of prevailing flexible care ethics being manipulated to result in a slippery slope to euthanasia.
\end{abstract}

\section{Introduction}

Compliance to strict guidelines is frequently what separates acceptable practices from those that are unsanctioned. This is particularly true of end of life interventions where it is feared misappropriation of sanctioned interventions will lead to disreputable practices. Such process are seen to at their most insidious when occurring almost imperceptibly through small breaches of guidelines that spiral into fully blown unacceptable practices [1]. One such example relates to the use and indeed perceived misuse of Continuous Deep Sedation (CDS) in the amelioration of intractable symptoms amongst the terminally ill where putative breaches in practice guides are seen as advancement of euthanasia or practices akin to it. Such a stance is unsurprising given the undocumented and undefined nature of this practice there is an inherent impetus to encapsulate cultural, religious and local beliefs within treatment goals [2-5].

This paper will focus upon this latter issue as an example of a Slippery Slope for the perceived potential for gravitation from a clinically proven treatment of last resort to a legally unacceptable intervention by comparing the application of the criteria and standard of care across several Confucian inspired countries to demonstrate the potential ethical issues that can result when the criteria is not rigidly followed. The focus of interest for such a postulation centres upon the working practices of palliative care teams in attempting to accommodate and respond appropriately to the demands and considerations of cultural, religious, psychosocial and local beliefs that sit at the core of its goal of holistic care provision [6-9]. It suggests that there lies a latent potential for abuse and misapplication of established treatment options when they are applied within the specific conditions set out by the demands of these sometimes fractious elements $[1,10$ 20]. Krishna, Holtedhal, van Delden, Jochemsen and Keown and Rietjens et al. report in a series of case reports and commentaries that these differences in opinion are underpinned by the wishes to alleviate pain and suffering which may sit diametrically opposite to wishes to maintain consciousness till the patient's demise in observance of a religious or cultural norms [4]. This paper will consider if the commodious and reflexive practices of a palliative care team, in its effort to meet its goals of providing holistic, culturally sensitive patient centred care may be subverted and misappropriated to make CDS, a nascent form of euthanasia.

\section{Continuous Deep Sedation (CDS)}

To begin with the term 'Continuous Deep Sedation' (CDS) relates to a proposed understanding of the practice of Terminal Sedation or Palliative Sedation and its ilk. Within the particularities of local practice, the term 'Continuous Deep Sedation' best captures the ideals of this practice. CDS is only utilised amongst patients with a prognosis of less than 2 weeks after superficial and intermittent sedation has failed and when all other means of ameliorating intractable symptoms have been exhausted. It is administered with the sole intention of relieving intractable symptoms in a justified, proportional and monitored manner that entails neither the routine cessation of Clinically Assisted Nutrition and Hydration (CANH) nor the abbreviation of life. Evaluation for the application of CDS is informed by a clear determination of the best interests of the patient after impeccable and thorough consideration of the patient's situation through the input and insights of a multidisciplinary team that includes the primary physician. This is particularly apt given that within most local practices, palliative care teams assume a purely advisory role and overall responsibility remains within the office of the primary physician. 
Under the auspices of the Multidisciplinary Team (MDT), all relevant clinical and nonclinical considerations leading up to the decision to utilize this option are rigorously documented, as are attempts at securing direct patient involvement in this process. Should this not be possible, due consideration upon the patient's previous wishes, goals, opinions and written statements ought to be made. This decision must be verified by the primary physician and by the MDT as a whole and implemented in accordance with clearly delineated guidelines [20-25]. It is with the primary physician that the final decision for the application of this palliative treatment of last resort rests $[9,10]$. The primary physician is also expected to ensure that all discussions with regards to the implementation of CDS are well documented and justified in order to maintain accountability and transparency of this process. Authorization in most cases are based upon holistic review and multidisciplinary determination of the patient's best interests $[9,10]$.

Taken within these specific parameters and given the clear empirical evidence attesting to its safety, the utilization of CDS sits quite apart from practices akin to euthanasia. Within the local context, CDS is viewed as a palliative treatment of last resort that does not seek to realize its goals of ameliorating suffering the attenuation of life. This goal is instead achieved through the meticulously monitored, proportionate, responsive and life preserving use of lowered consciousness administered by the specialist palliative care team in keeping with the adapted clinical guidelines set out by the Royal Dutch Medical Association and the European Association for Palliative Care (EAPC) recommended framework for the use of sedation in palliative care [21-35].

As a result SSAs have shifted their focus to the manner palliative care HCP must contend and impregnate working practices with individualistic concepts of religious, cultural and local beliefs to better meet their goals of care. It is posited that through such accommodating and responsive practices, infringements of recognised and accepted treatment approaches will become endemic leading finally to disreputable practices. Taken within the context of this example, the protracted and repeated violations of CDS protocols in meeting the goals set out by social, cultural and local mores will lead insidiously but pertinaciously to euthanasia.

\section{Slippery Slope Argument (SSA)}

Led by an obligation 'to do no harm', physicians are instructed to be mindful of not only their actions but the possible repercussions of their interventions. Pertinently, HCPs need to be cognizant as to how their actions may 'snowball' to conjure some disservice to the patient, their family or to the public as a whole. This admonitory view often takes the form of a Slippery Slope Argument (SSA).

In the case at hand, the SSAs highlight concerns associated with the use of CDS and its apparent portent of euthanasia and its kin. The basic argumentum that SSAs hold is that euthanasia is morally abhorrent and its practice and those akin to it should be vitiated. It proceeds to reason that as a result of its close confederacy, the administering of CDS should also be proscribed for fear that it will trumpet the acceptance and use of this vexed intervention either directly or 'by the back door' or the incipience of analogous practices. For the most part such SSAs are needlessly dramatic, unrealistic and make no attempt to align such an appraisal of circumstances with empirical evidence or clinical practice presented above. Indeed it does little to integrate such practices with neither the nuanced end of life care within Singapore nor the prevailing evidence to the safety of CDS [26-52]. Given the empirical data as to the safety of the practice of CDS and the distinctive local palliative care practices observed, many traditional SSAs linking CDS with hastening death can be dispensed with [26-52]. However these very unique particularities of Singaporean medical practice that reinforce the safety of CDS and countenance its application under the auspices of palliative care also enveigle concerns of other elements of palliative care practices [2-5, 53-55].

It is upon the requirement to integrate cultural, societal and religious considerations within practice that some SSAs seek to apply their central machinations upon. Here the principal premise of the 'dialectic impotence' purports that physicians are incapable of preventing apparently innocuous breaches in practice as they meet the culturally relevant, religiously sensitive, socially acceptable particularized goals of care of the patient, from 'snowballing' into larger and unacceptable clinical conduct. These transgressions may take a number of forms. Conspicuous amongst them are the progressively ambiguous processes called upon to accommodate the vast variances in local culture, beliefs, spirituality and social facets to individualized palliative care and treatment goals. It is suggested that through such pliability, insight maybe lost, judgment clouded, and intentions skewed within practices that are increasingly difficult to scrutinize. Additionally accepted working practices may be altered and guidelines breached within this individualized approach. Such processes will affect progressive rifts in working practices that will eventually lead either to frank euthanasia or practices of the same character.

Essentially an SSA built upon this framework can be viewed as comprising of Premises (P) that lead unshakably to Conclusion (C). It argues that accepting P1 will lead to the acceptance of P2 and P3 and thus outcome C1 and can be viewed thus

P1-Palliative Care practices patient centred care and therefore tailors its practices to meet the goals and specific considerations of each individual

P2-Such practice calls for flexibility in working practices that require unorthodox and sometimes indulgent practices to meet the specific goals of each patient and their family

P3-Under such situations, serial breaches in accepted CDS protocols will be inevitable and surely lead to the advent of euthanasia or similar practices

\section{C1-Therefore CDS should not be allowed}

Whilst SSAs chose to focus on this rather large area of consideration, it would be foolhardy of this paper to attempt to address the many facets within the myriad of considerations 
that are inferred to by these SSAs. For the purposes of this paper, focus will instead be upon the influence of the family within the local context given that it highlights many of the psychosocial, financial, cultural and religious considerations that the SSAs allude to. Using the example of the psychosocial and cultural practices within a Confucian inspired family centric society such as Singapore we study the potential for prevailing practices to precipitate the concerns raised by these SSAs.

The SSAs argue that fulfilling the central goals of holistic end of life care that is aspired to by good palliative care will need increasing accommodation to the requests and sometimes demands of the family that in turn will blur practices and leave it pliable to manipulation. Within this example it needs to be stressed that the fluidity that occurs naturally within such complex social, psychological and clinical interactions and ensuing balancing will be replaced by a 'snap shot' view of the situation for the purposes of this paper. In practice, the evolving nature of the situation requires regular appraisal and refinement as clinical and psychosocial conditions alter.

\section{Practical Ethical Considerations}

In order to appreciate the practical ethical considerations and the complexities of the arguments that will be forwarded, an appreciation of the background to the debate is required. The particular area of focus of this paper will be that surrounding the position of the family within the decision making process and the accommodations that are required of palliative care HCPs in their treatment approaches. To clarify this situation, some local considerations will be provided to better inform this discussion.

\section{The position of the family}

The position of the family unit within the decision making process at the end of life in Singapore context is poorly delineated despite being rooted in family centric ideals [55-85]. Whilst similar societies exist in China, Taiwan, Hong Kong and Macau, it is to the Singaporean society that attention regarding end of life decision making and the influence of the family has been growing [86-112]. It is also in Singapore and only recently within China has Confucian principles been imbued in legislature such as the Maintenance of Parents Act 2010, Healthcare Financing, Medical Savings Accounts (Medisave and MediFund) and in the dispensation of financial support based upon the family's rather than the individual's abilities [112-130]. Indeed Khan in his report for the World Bank in 2001 reported that many social, financial and health provisions within Singapore remain Confucian influenced [59].

As a result of this Confucian family centric approach, local families play a number of roles that include the role of a surrogate in decision-making, an executor of post-mortem wishes, a psychologist, the main provider of physical care, a minister to spiritual needs and a provider in financial matters [55-85]. However there are clear differences and variations in adherence and piety to these duties and roles even within individual family units that prevents simple generalizations from being drawn [55-85]. This in turn reaffirms the need for an individualised approach to care provision that is proportional, holistic and reflexive in keeping with the central tenets contained within the definition of palliative care forwarded by the World Health Organisation (WHO) [6].

Here palliative care is seen as "an approach that improves the quality of life of patients and their families facing the problem associated with life-threatening illness, through the prevention and relief of suffering by means of early identification and impeccable assessment and treatment of pain and other problems, physical, psychosocial and spiritual. Palliative care

- Provides relief from pain and other distressing symptoms;

- Affirms life and regards dying as a normal process;

- Intends neither to hasten or postpone death;

- Integrates the psychological and spiritual aspects of patient care;

- Offers a support system to help patients live as actively as possible until death;

- Offers a support system to help the family cope during the patients illness and in their own bereavement;

- Uses a team approach to address the needs of patients and their families, including bereavement counselling, if indicated;

- Will enhance quality of life, and may also positively influence the course of illness;

- Is applicable early in the course of illness, in conjunction with other therapies that are intended to prolong life, such as chemotherapy or radiation therapy, and includes those investigations needed to better understand and manage distressing clinical complications [6].

Divining the position afforded to the family by such a definition, unearths a number of significant requirements for HCPs to be cognizant of, these include the need to

1. Consider the family on equal footing as the patient

2. Enhance the family's quality of life [QoL]

3. Relieve and indeed prevent suffering of the family in addition to the patient

4. Treat any physical, psychosocial and spiritual problems of the family in addition to the patient

5. Support the family throughout the illness

6. Support the family through the bereavement process

Furthermore HCPs need to involve the family in the following

1. Assessing the patient for psychosocial, psychological and spiritual aspects as part of a holistic assessment

2. Providing a support system to help the patient live as active a life as possible

Viewed within the local context, this definition in entreating 
palliative care HCPs to provide for the needs of patients and family with equal consideration gives credence for the distinctive position the family occupy within the decision making process. This would appear apt given that for $50 \%$ of interviewed palliative care patients and their caregivers in Singapore interviewed by Ho et al reported that the position of the family is seen as singular and familial determination within any deliberation far surpasses the import of any individualistic consideration [89]. Furthermore for a significant number of remaining respondents, the position within the nucleus of any consideration is in fact a shared affair between the patient's own views, those of the family and HCPs in equal measure [89]. This position echoes those findings both in other studies in Singapore and in neighbouring Malaysia [9096,113].

Interestingly data from Ching et al, Yang et al and Foo et al. also reveals that a purely patient centred approach that would disregard the input of the family is hardly ever reported $[91,92,95]$. Ho et al reported that in about a third of cases however patients reported that it was then that made the final decision albeit with input from their family [89]. The presence of such disparity in perception calls for flexibility in practice to allow palliative care HCPs to better meet their prime directives and the importance of integrating the input of families in decision making process.

However such adaptability in reconciling the various influences of spiritual, cultural, social and local customs that run parallel to as well as imbue the position adopted by the family within the decision making process appear to have lent credence to the assertions of SSAs that such suppleness of practice would constitute the 'first step down the slippery slope' [55-86]. This is particularly so given that such decisions may disregard the wishes of the patient and may belie the belief that the interests of the family and those of the patient are always aligned. In effect it is suggested that in allowing the family such dispensation to determine treatment approaches within the decision making process, their increasing penchant to ignore medical advice and act upon sometimes questionable motivations is taken to be the sentinel act that predisposes this accepted practice to corruption. Within the example of CDS, the validated albeit translocated and manipulated evidence of the strength and depth of familial determination raises the concern that it may be exploited to other ends.

To comprehend the enormity of such a posit, its impact upon care provision and the concerns underlying such a familial driven decision making process, it is important to consider the basis, influence and impact of familial determination upon local practice.

\section{Familial Determination}

Familial determination that sits within the central tenets of familialism is steeped in cultural, social and local tradition that cannot be readily discounted. Its roots now appear to extend far beyond simple sociocultural considerations to involve a number of local psychosocial and economic features. So strong is its influence locally that it remains a frequent observation that decisions pertaining to care stances remain the express domain of families rather than patients themselves. Indeed familialism, which is loosely defined as 'a social pattern in which the family assumes a position of ascendance over individual interests', appears to abjure to such a stance [87]. Veritably it is not uncommon for the patient to not be in receipt of the full facts of his or her condition as a result of familial collusion. This praxis is in turn fuelled in part by another societal and cultural requirement, which pertains to the need to maintain hope amongst patients irrespective of race or culture in Singapore [88-116]. Underlying such a concept is the local credo that a harmonious and calm lifestyle, free of distress and consternations enhances life expectancy. These local mores then affirm the practice of collusion and nondisclosure and even sometimes adjudges the act of misleading the patient, to be acceptable [82-84,101-116].

Familial determination also finds support amongst some quarters of local society where discussions about death or indeed the breaking of dire news, is held to be inauspicious and even regarded as taboo, preventing some families from broaching these difficult issues with patient and resulting in their being thrust with the role of the main decision maker [82-84,101116]. A further rational albeit one that merely supports direct family involvement in the decision making process pertains to the issue of the costs incurred in caring for the patient, be it at home, the hospice or in an acute setting. To begin with, Singapore employs a system of shared responsibility for health care, resulting in a co-payment scheme [117-125]. As a result, as Singaporeans contribute into an individual medical savings plan. That is designated for the cost of his or her medical costs, called Medisave [117-125]. When this is exhausted, family members can elect to draw upon their own Medisave accounts to pay for the care of their loved ones. However Medisave itself doesn't cover all the costs and the cash 'top ups' that are required are sometimes passed on to the family who in turn have a legal obligation to provide financial support to immediate members of their family (ref below). Given this wider implication to the family unit, familial determination is felt to be justified as it is the family unit that will be impacted on by any care decision. Indeed the incurring of such costs may lead to significantly differing decisions being made from situation to situation even within the same family unit.

A recent case that highlights this is the case of a young lady with a hematological malignancy who opted not to have treatment despite the reasonable chance of remission offered by western care. She did so having exhausted her own Medisave and decided to after conferring with her family, to protect the future welfare of her younger siblings by opting to conserve the family's meagre financial resources for their education. She opted instead for the cheaper traditional medicine option in neighbouring Malaysia. It was never clear the influence of the family wielded upon her decisions however it did appear that her father at least was keen on this option and she had, prior to this point, always crafted her decisions in accordance to her father's wishes. She passed away not long after. 


\section{Filial Piety}

Protecting the interest of the individual within the familial decision making process lies within the domain of filial piety, which behold the younger generation to care and protect the best interests of their elders [27-36],([35,38] BIP NE). Compliance to this expectation is policed by the wider family and community elders through reliance upon an inherent local need to preserve 'face' within the community [52]. Maintenance of'face' or personal honor and dignity feeds upon an underlying aversion of familial and societal disapproval [52]. Veritably failure to meet filial obligations in the eyes of the wider family and community will result in a loss of 'face' whilst meeting such expectations will see one's 'personal stock' rise [52,100]. Whilst traditionally believed to be a uniquely Chinese idea encapsulated with Confucian beliefs, recent study on this element shows that it to be largely adopted by the other races in Singapore [5-8,16-21,23,24,26,27]

Indeed filial piety impacts local laws and has been viewed as both the root and bane of some local legislation. It occupies premier importance within the Maintenance of Parent Act (2010), which cements recognition and familial obligations of children towards the upkeep of their parents [126]. Conversely it is fated as a reason for the relatively low uptake of Advanced Medical Directives in Singapore. Here the position of the family as the main surrogates and protectors of the interests of the individual appears to negate the need, in the minds of many, for such legislature. Familial determination and filial piety however also come to conflict with the atomistic view of self determination contained within the opt out Human Organ Transplant Act (HOTA) programme. Here HOTA dispenses with the input of the family unit upon an individual's decision to remain an organ donor much to the chagrin of some elements of the community [127-130].

Traditional interpretations of this concept which is largely Confucian in origin requires a more contemporaneous comprehension of this evolving notion particularly in the light of increasing western ethical influences and Judean- Christian values amongst the local population [4,55-85]. Fluidity of conception of 'face' too has been seen in the local clinical settings. Driven by a desire to not be seen to be abandoning their loved ones or be accused of not to have 'cared enough' have seen families requesting for interventions even in the face of medical advice to the contrary $[4,55,85]$. Accidence to such requests, at least through a circuitous deliberative process, would appear to countenance fears of the 'first step down the slippery slope'.

\section{Mechanisms of the Slippery Slope}

This last statement aptly introduces Burgess's first mechanism of the SSA, which posits the application of translocated information from one setting to another clinically dissimilar context [1]. Within the example above, acquiescing to the prolongation of futile treatment at the end of life, for example feeding is translocated to a posit that it will leave physicians keen to oblige family wishes and in turn affect a change in practice that would cease life saving interventions upon the request of the family.
Consider the recent case of Madam Norin, a 42 year old Malay lady who was diagnosed with oropharyngeal cancer. Despite her poor prognosis and increasingly frail state, which required her to be artificially hydrated, her siblings were keen to take her on pilgrimage to Mecca during Ramadan. They were also keen that her hydration be ceased at least momentarily during the fasting hours in observance of her beliefs. They cited the fact that whilst not expected of her, she had always abided by her religious duties and observed the fast during the holy month even amidst her multiple lines of chemotherapy. They were aware that the heat and sun exposure that Norin would endure during her Umrah (pilgrimage) would place her at risk of dehydration and other life threatening collieries but nonetheless they felt that such actions would be in keeping with her wishes, cultural and religious beliefs.

An important point of consideration is the fact that Nurin herself never envisaged an Umrah at any point of her illness though she had hoped to carry out a Hajj prior to the onset of her illness. The family were keen to bring this to fruition, particularly in the face of pressure to do so from some of the family elders. They understood that she would not be able to wait till the Hajj period, so decided to grant her wish in this manner. They were advised that such a pilgrimage during the Eid- al Fitri period would be just as meaningful and were also told that death in Mecca during a pilgrimage was to be considered a blessing and thus despite its risks, a worthy endeavour.

Additionally given that Nurin was prone to agitation particularly with transfers between the many sites of worship and the inevitable change of environment, the family was keen that she be sedated once the last devotions are carried out and offered to do so given that they would be accompanied by a cousin of theirs who was a nurse.

Such a request created some concern amongst the members of the MDT however when it became clear that there were some amongst the family that were willing to take the patient to Mecca against medical advice and even without any medication despite her precarious state, it quickly became clear to the team that some input was needed for the greater good of the patient. In deference to these requests, the palliative team advised the family as to how these religious, familial and cultural goals might be met and provided them with means of sedating and rehydrating her before the family flew to Saudi Arabia. Nurin passed away in Mecca on the night her pilgrimage was completed and was buried there.

This compliance and adaptation of practice whereupon potentially life shortening interventions are permitted, including the cessation of fluids and the unsupervised use of sedatives under the aegis of respecting cultural, religious and social differences forms an example of the central posit of the SSA that is to be presented. Here all these factors are crystallized within the actions of the family. The belief is that in acceding to the family's wishes in such a manner means that such an unsupervised practice has been allowed to take a foothold in what is regarded as accepted practice of sedating agitated patients albeit in a 
supervised and monitored manner. It is argued further that as a result the precedent set by Nurin's case, will allow for the catering of other more sinister proclivities.

With this example in mind, an SSA may appear thus

P1-Palliative Care practices patient centred care and therefore tailors its practices to meet the goals of each individual within which familial choices need to be considered. Furthermore as we know from clinical experience and published data

a. familial determination is a potent force to be considered within any decision making process $(4,55,85)$

b. Families are increasingly eager to maintain 'face' in end of life decision making which in the case of Nurin, took the form of ensuring that she fasted and carried out her Umrah. This the family felt would negate any ongoing concerns the family elders had and any reservations that the wider family might have as to whether they had done all they could to meet her religious and existential needs [55]. Here her continued but episodic confusion was viewed upon as a sign of emotional, existential and spiritual distress spurring the family, in part, to visit this idea of an Umrah.

c. Families are increasingly prepared to countermand medical advice. Some are eager to continue treatments and feeding even in the face of medical determinations of futility whilst others, as was the case of Nurin, cease it against medical advice $[4,55,85]$.

P2-Such practice calls for a holistic understanding of the various psychosocial, Mexistential and cultural factors involved, flexibility in working practices that require unorthodox and sometimes indulgent practices to meet the specific goals of each patient and their family. In the case of Nurin, the prescribing of sedatives to be used at the discretion of the family could be viewed as worrisome as would the act of discontinuing hydration in such difficult circumstances.

P3-Under such situations, the provision of sedatives to unsupervised members of the family augurs increasing breaches in accepted practice guidelines will be inevitable and surely lead to the advent of euthanasia, PAS, VAS and even involuntary euthanasia. In the case of Nurin, this also took the form of cessation of fluids despite local standards of CANH maintenance even at the end of life and the potential misuse of sedatives particularly in the untrained hands of the family members.

P4-Upon such a scenario, recognized treatment protocols such as those seen for the application of CDS will be compromised and misappropriated. The precedent set here would be allowed to grow and lead to further beaches.

\section{C1-Therefore CDS shouldn't be allowed.}

This SSA premises that in attempting to accommodate the inherent differences that exist within each clinical case; goals of care and management plans need to be inclusive, flexible and reflexive so as to meet the demands of these individual goals and changing conditions. As a result of such a commodious and liberal work ethic, this SSA posit that the boundaries of acceptable practice will be gradually eroded, resulting in 'creeping breeches of the line' that will eventually abrade and advance the confines of acceptable working practice till at last previously unacceptable processes become common everyday praxis.

It attempts to pre-empt any reliance upon established guidelines and the presence of the MDT that would both police and steer practice, by stating that a focused approach toward patient centred goal is necessarily dependent upon such flexibility and predisposed to interpreting the 'spirit' of clinical guidelines rather than rigid adherence to them. As a result, monitoring practice will be difficult, motivations may be clouded by competing interest and external pressures, clinical judgments too may be compromised as a result of increasing bonds that may form between patients, their family and HCPs in their close interactions and guidance for HCPs may be limited as such situations such a Nurin's become complex and pressured. This predisposes to a 'fallacy of the heap' argument where increasing breaches in these guidelines will lead to an inevitable descent into disreputable practices.

This SSA highlights both Burgess's posits on the mechanism for SSAs. As stated Burgess's first mechanism suggests the application of translocated information from one setting to another clinically dissimilar context [1]. There are 2 presumptions here. The first conjecture is that if families begin countermanding physicians in one aspect of end of life care, they are liable to do so in other areas too. The second relates to the evidence that physicians frequently cede their authority in end of decision making to the family and the belief that they are liable to continue on such a trajectory and acquiesce to further demands. The postulated end result of such combination of actions is to purport a 'snowball' effect that will eventually see it possible for families or even the HCPs to implement life abbreviating procedures.

The logic on the surface may not be as difficult to follow given that financial consideration and care burdens particular to the local context may induce families to 'draw the line' as to the lengths they would go to maintain the life of the patient and compel them to decide upon interventions that may not be in the patient's best interests. The logical conclusion at the end of such a 'flight of ideas' is the advent of euthanasia.

Burgess' second mechanism of SSA proposes an 'attitude altering slippery slope' where a growing habituation to breaches of guidelines is seen in accommodation of local cultural, societal and religious practices is seen paving the way to an increased acceptance of irregular practices and eventually to life abbreviating practices [1].This Burgess postulates emerges within a desensitized society where sensitivities and objections associated with this practice gradually ebb away and in its place materializes an acceptance that euthanasia masquerading as CDS was already standard clinical practice leaving little reason to object to the unadulterated form of the practice [1]. Here Burgess conceives that along with the dissolution of resistance to its use, the original rationale for the implementation of this 
practice is also 'lost' through time enabling further abuse of this intervention [1]. Proponents of the slippery slope state look to the Netherlands as just such an example [12-17,131-133].

Similarly there is also a need to stress that these changes needn't take the form of a linear or singular precipitous decent but could make for multiple small almost imperceptible slippages that only when viewed together in their entirety reveal the true extent of the slide [1]. As a result it is feared that boundaries begin to bend or indeed simply become porous in an effort to assuage these mounting demands of individualized, culturally pertinent, religious sensitive, socially conscious care [53, 54]. Could it be in our haste to provide patient centred care we contrive to blur our boundaries? Would it not be possible that given the level of involvement and interactions with patients and their families; complex relationships arise that may cloud the judgments of health care professionals and compromise boundary management or even breaching guidelines and rules?

Consider the case of Hishamudin who following his diagnosis of cancer of the scrotum, chose to employ Traditional Malay Medication (TMM) in addition to his convention chemo and radiotherapies. Interestingly it was observed that the TMM concoction that he imbibed daily, contained steroid like properties that in turn predisposed him to infections as did his chemo and radiotherapy. Its affects were supplemented by a topical potion that was applied to the affected skin, which appeared to have some detrimental effects to wound containment. Additionally as a result of his wish to continue with his prayers 5 times per day, the family requested a decrease in his level of hydration and the duration of his antibiotics due to their propensity to increase his toileting needs and interrupt his ablutions. His antibiotics were duly curtailed and the diuretics ceased, due largely to his families resistance in administering them even though they witnessed the effects of their noncompliance by the increasing oedema and cellulitis, Hishamuddin endured compounded by their persistence in administering topical TMM mixtures against medical advice.

Given that he was being nursed at home, there was little that the health care team could do but to explain and stress the rationale for their advice. Yet for the sake of the patient's care needs, they worked together with the family in coming to a compromise with the use of the tinctures and other medications. This pragmatic approach was in part due to the acceptance that they were in keeping with the patient's cultural beliefs and local mores and the fact that the patient was already quite ill by this time. He passed away not long after.

Here the breaches in guidelines in an attempt to meet the goals of the family appear to have combined to hasten death. This highlights an added dimension to prevailing considerations that highlight the fact that multiple small almost imperceptible slippages may culminate in a singular precipitous decent that need to be viewed in their entirety to reveal the true extent of the slide [1]. A recent article on the shifting goals of care in Singapore to better accommodate the wishes of the family simply highlights the need to be cognizant of these influences and their effects on how clinical services are offered in different settings $[4,55,85]$.

\section{Firm response}

The examples thus far relate to the countenancing of medical practice to familial requests and in so doing setting the precedent for the likely continued compliance in such wishes by HCP that would see families become the primary determiners of treatment approaches even at the cost of being contrary to the patient's own wishes, their best interests and the advice of HCPs. Applied to the end of life care scenario and CDS in particular simply to comply with the culturally and socially reinforced practice of familial determination could be seen to precipitate an irretrievable descent down the slippery slope to overt euthanasia.

A firm riposte to such SSAs must lie in uncoupling the proposed procession of thought that promulgates a necessary continuity of actions and the unremitting descent to euthanasia [16]. This most potent sting does not lie within these appeals to breaches in codes of conduct or trituration of moral values but in its strong psychological roots. Central to its persistence within bioethical considerations is its invocation of the common human tendency to assimilate closely related but easily distinguished and clearly flawed material. This coadunation of factors and flawed reasoning creates the illusion of the existence of this downward spiral [17]. Indeed whilst the evidence for these apparent descents remains small and the elements of self awareness and awareness of the limits of practice and ethics have been frequently discounted, there is sufficient suspicion to prevent its outright dismissal from considerations and the continued bolstering of its viability within the medical circles [18-20].

However armed with the knowledge that intention can be elucidated, the presence of the holistic and qualified deliberative support of the MDT, the increasing of patient driven goal setting and the infusion of evidenced based practices, the presence of innate regulators within the person of HCPs all point to a solid defense. Clearly, the SSA; simple in structure, specific in scope, over reaching in goals; appears deficient in logical rigor and evidential underpinning, leaving it tantamount to an ethical flashing amber light at a zebra crossing.

Some authors have been no less circumspect in their analysis referring to SSAs as an "intuition pump" that simply plays upon people's fears to forward their own goals [134-136]. Veritably SSAs adjuring to latent fears fuelled by Nazi- style slides into genocide appears to be exaggerations, even amongst Holocaust survivors, lacking bite. However their bark may still have a role in highlighting chilling possibilities of any intervention [134-136].

Importantly within the context of this paper, there is an acceptance that there is a potential for a slippery slope but given the sociocultural considerations and the inherent legislative stance particularly amongst a population still largely led by the regnant religious beliefs and cultural norms of this island city, the anticipated snowball effect appears to be overstated.

These local cultural factors along with legal constraints, strong teamwork and responsible and accountable working patterns as well as ethical oversight will also instruct team members upon practical issues, further preventing the misapplication of a 
reflexive, expansive, accountable and responsive work ethic to the unlikely use of CDS as a form of euthanasia.

\section{References}

1. Burgess JA (1993) The great slippery-slope argument. J Med Ethics 19: $169-174$

2. Rietjens JAC, van der Heide A, Onwuteaka-Philipsen BD, van der Maas PJ, van der Wal G (2005) The practice of terminal sedation in the Netherlands. Ned Tijdschr Geneeskd 149: 467-471.

3. Rietjens JAC, van Delden JJ, van der Heide A, Vrakking AM, OnwuteakaPhilipsen BD, et al. (2006) Terminal sedation and euthanasia: a comparison of clinical practices. Arch Intern Med166: 749-753.

4. Krishna L (2011) Decision making at the end of life: A Singaporean Perspective. Asian Bioethics Review 3(2): 118-126.

5. Krishna L (2011) The Position of the Family of Palliative Care patients within the Decision Making Process at the end of life in Singapore. Ethics and Medicine 27(3):185-192.

6. http://www.who.int/cancer/palliative/definition/en/

7. Krishna LRK (2012) Best Interests Principle in the determination within the Singapore context. Nursing Ethics 19(6): 787-799.

8. Hanks DD, Cherny NI, Christakis NA, Fallon M, Kaasa S, et al. (2003) Textbook of Palliative Medicine. Oxford University Press.

9. Volokh E (2003) The Mechanisms of the Slippery Slope. Harvard Law Review 116: 1028-137.

10. Krishna L, Chin J (2011) Palliative Sedation within the Duty of Palliative Care within the Singaporean Clinical Context. Asian Bioethics Review 3(3): 207-215.

11. Holtedhal K (1994) Euthanasia: the Slippery Slope. Correspondence. Family Practice 11(1): 95.

12. van Delden JJ (1999) Slippery Slopes in the Flat countries--a response. J Med Ethics 25: 22-24.

13. Jochemsen H, Keown J (1999) Voluntary euthanasia under control? Further empirical evidence from the Netherlands. J Med Ethics 25: 1621.

14.Gillon R (1999) Euthanasia in the Netherlands: Down the Slippery slope? J Med Ethics 25(1): 3-4.

15. Ogilvie AD, Potts SG (1994) Assisted suicide for Depression: The Slippery slope in action? BMJ 309(6953): 492-493.

16. Boer TA (2003) After the Slippery Slope: Dutch Experiences on regulating active euthanasia. J Soc Christ Ethics 23(2): 67-83.

17. Lafollette H (2005) Living on a slippery slope. J Ethics 9(3/4):475-499.

18. http://csjarchive.cogsci.rpi.edu/proceedings/2006/docs/p1145.pdf

19. Corner A, Hahn U (2007) Evaluating the Meta-Slope: Is there a Slippery Slope Argument against Slippery Slope Arguments? Argumentation 21: 349-359.

20.Gottlieb MC, Yonggren JN (2009) Is There a slippery slope? Considerations regarding multiple relationships and risk management. Professional Psychology: Research and Practice 40(6): 564-571.

21.http://knmg.artsennet.nl/uri/?uri1/4 AMGATE_6059_100_TICH_ R193567276369746.

22. http://www.palliative.org/PC/ClinicalInfo/Clinical\%20Practice $\% 20$ Guidelines/PDF\%20files/3A6\%20Palliative\%20Sedation\%20a\%20 nd\%20Addendum.pdf
23. Verkerk M, van Wijlick E, Legemaate J, de Graeff A (2007) A national guideline for palliative sedation in the Netherlands. J Pain Symptom Manage 34(6): 666-670.

24. Cherny NI, Radbruch LE (2009) European Association for Palliative Care (EAPC) recommended framework for the use of sedation in palliative care. Palliat Med 23(7): 581-593.

25. Kohara H, Ueoka H, Takeyama H, Murakami T, Morita T (2005) Sedation for Terminally Ill Patients with Cancer with Uncontrollable Physical Distress. J Pallia Med 8(1): 20-25.

26. Mount B (1996) Morphine drips, terminal sedation, and slow euthanasia: definitions and facts, not anecdotes. J Palliat Care 12 (4): $31-37$

27. Enck RE (1991) Drug-induced terminal sedation for symptom control. Am J Hosp Palliat Care 8(5): 3-5.

28. Ventafridda V, Ripamonti C, De Conno F, Tamburni M, Cassileth BR (1990) Symptom prevalence and control during cancer patients' last days of life. J Palliat Care 6(3): 7-11.

29. Greene WR, Davis WH (1991) Titrated intravenous barbiturates in the control of symptoms in patients with terminal cancer. South Med J 84(3): 332-337.

30. Morita T, Inoue S, Chihara S (1996) Sedation for symptom control in Japan: the importance of intermittent use and communication with family members. J Pain Symptom Manage 12(1): 32-38.

31. Morita T, Tsuneto S, Shima Y (2001) Proposed definitions of terminal sedation. Lancet 358(9278): 335-336.

32. Morita T, Muller-Busch C, van Heest F (2010) Sedation in Palliative Care- Definitions and Terminology. European Association for Palliative Care.

33. Rousseau PC (2002) Palliative sedation. Am J Hosp Palliat Care 19(5): 295-297.

34. Fainsinger R, Miller MJ, Bruera E, Hanson J, Maceachern T (1991) Symptom control during the last week of life on a palliative care unit. J Palliat Care 7(1): 5-11

35. Fainsinger RL, Landman W, Hoskings M, Bruera E (1998) Sedation for uncontrolled symptoms in a South African hospice. J Pain Symptom Manage 16(3): 145-152.

36. Stone P, Phillips C, Spruyt O, Waight C (1997) A comparison of the use of sedatives in a hospital support team and in a hospice. Palliat Med 11(2): 140-144

37. Peruselli C, Di Giulio P, Toscani F, Gallucci M, Brunelli C, et al. (1999) Home palliative care for terminal cancer patients: a survey on the final week of life. Palliat Med 13(3): 233-241.

38. Quill TE, Lo B, Brock DW (1997) Palliative options of last resort. A comparison of voluntary stopping eating and drinking, terminal sedation, physician- assisted suicide and voluntary active euthanasia. JAMA 278(23): 2099-2104.

39. Cherny NI, Portenoy RK (1994) Sedation in the management of refractory symptoms: guidelines for evaluation and treatment. J Palliat Care 10(2): 31-38.

40. Chater S, Viola R, Paterson J, Jarvis V (1998) Sedation for intractable distress in the dying - a survey of experts. Palliat Med 12(4): 255-269.

41. Menten J (2003) Cancer pain: interdisciplinary and comprehensive management. Lambert Academic Publishing, Australia.

42. Morita T, Akechi T, Sugawara Y, Chihara S, Uchitomi Y (2002) Practices 
and attitudes of Japanese oncologists and palliative care physicians concerning terminal sedation: a nationwide survey. J Clin Oncol 20(3): 758-764.

43. Morita T, Hirai K, Okazaki Y (2002) Preferences in palliative sedation therapy in the Japanese general population. J Palliat Med 5(3):375385.

44. Rietjens JAC, van der Heide A, Vrakking AM, Onwuteaka-Philipsen BD, van der Maas PJ, et al. (2004) Physician reports of terminal sedation without hydration or nutrition for patients nearing death in the Netherlands. Ann Intern Med 141(3): 178-185.

45. Krishna L, Poulose JV, Tan BSA, Goh C (2010) Artificial Hydration at the end of life in an Oncology Ward in Singapore. Indian J Palliat Care 16(3): 168-173.

46. Radha Krishna LK, Poulose JV, Tan BS, Goh C (2010) Opioid use amongst cancer patients at the end of life. Ann Acad Med Singapore 39(10): 790-797.

47. Miccinesi G, Rietjens JA, Deliens L, Paci E, Bosshard G, et al. (2006) Continuous deep sedation: physicians' experiences in six European countries. J Pain Symptom Manage 31(2): 122-129.

48. Quill TE, Lo B, Brock DW, Meisel A (2009) Last- Resort options for palliative sedation. Ann Intern Med. 151(6): 421-424.

49. Claessens P, Menten J, Schotsmans P, Broeckaert B (2008) Palliative sedation: a review of the research literature. J Pain Symptom Manage 36(3): 310-333.

50. Sales JP (2001) Sedation and terminal care. Eur J Palliat Care 8: 97100.

51. Wein S (2000) Sedation in the imminently dying patient. Oncology 14(4): 585-601

52. Beel A, McClement SE, Harlos M (2002) Palliative sedation therapy: a review of definitions and usage. Int J Palliat Nurs 8(4): 190-199.

53. Goh CR (2008) Challenges of cultural diversity. In J Beattie \& S Goodlin (eds.), Supportive Care in Heart Failure. Oxford University Press, United Kingdom, pp. 451-461.

54. Goh CR (2008) Culture, ethnicity and illness. In TD Walsh, AT Caraceni, R Fainsinger, KM Foley, P Glare, C Goh, M Lloyd-Williams, JN Olarte \& L Radbruch (eds.), Palliative Medicine, Saunders Elsevier, USA, pp. 5154.

55. Ho ZJ, Radha Krishna LK, Yee CP (2010) Chinese Familial Tradition and Western Influences: A Case Study in Singapore on Decision Making at the end of life. J Pain Symptom Manage 40(6): 932-937.

56. Chan D (2001) Survey on Social Attitudes of Singaporeans (SAS).

57.Tan CB (1983) Chinese religion in Malaysia: A general view. Asian Folklore Stories 42(2):217-252.

58. Lee TS (2007) Chinese Theatre, Confucianism and Nationalism: Amateur Chinese Opera Tradition in Singapore. Asian Theatre Journal 24(2) :397-421.

59. Khan H (2001) Social Policy in Singapore. A Confucian Model? WBI Working Papers. World Bank Institute Publications. Vernon.

60. Ngiam TL (2002) Inclusion of people with disabilities: policies and services. In Tiong TN \& Mehta KK (eds.), Extending frontiers: social issues and social work in Singapore. Eastern Universities Press, Singapore, pp. 154-173.

61.Tan EKB (2003) Re-engaging Chineseness: political, economic and cultural imperatives if nation-building in Singapore. The China Quarterly 175: 751-774.

62. Tan EKB (2007) Harmony as ideology, culture and control: Alternative dispute resolution in Singapore. Asian Law 9(1): 120-151.

63. Aspalter C (2006) The East Asian welfare model. International Journal of Social Welfare 15: 1-12.

64. Mok KH (2000) Impact of globalization: a study of quality assurance systems of higher education in Hong Kong and Singapore. Comparative Education Review 44(2): 148-174.

65. Mok KH (2003) Decentralization and marketization of education in Singapore: a case study of the school excellence model. Journal of Educational Administration 41(4): 348-366

66. Aaron K (2005) Imagining the Singapore "nation" and "identity": The role of the media and national education. Asia Pacific Journal of Education 25(1): 75-91.

67. Koh TTB (2000) Asian values reconsidered. Asia-Pacific Review 7(1): 131-136.

68. Moon CI, Prasad R (1998) Networks, politics and institutions. In S Chan, C Clark \& D Lam (eds.), Beyond the developmental state: East Asia's political economies reconsidered. Macmillan Publishers, England, p. 9-25.

69. Ngiam TD (2006) A mandarin and the making of public policy, National University of Singapore Press, Singapore.

70. Chua BH \& Kuo ECY (1991) The making of a new nation: cultural construction and national identity in Singapore, National University of Singapore, Singapore, pp. 104.

71. Nguyen PM, Terlouw C, Pilot A (2005) Cooperative learning vs. Confucian heritage culture's collectivism: Confrontation to reveal some cultural conflicts and mismatch. Asia Europe Journal 3(3): 403419 .

72. Brydon K (2011) Changing face for social work: Globalization, Internationalization and the Monash BSW in Singapore 2004-2006.

73. Kuah KE (2007) Confucian ideology and social engineering in Singapore. 20(3): 371-383.

74. Tarmugi A (2000) Preserving family ties and family values. Luncheon Talk on "Family Values" at the United Nations Association of Singapore (UNAS).

75. Singapore. Shared Values. White Paper. 2 Jan 1991.

76. Lim MSL "Shared Values" \& their role in Singapore's evolving ideological framework.

77.Teng YM, Hock KS (2010) The greying of Singapore's population: Prospects and challenges. In panorama: Insights into Asian and European affairs. Konrad-Adenauer-Stiftung, Hofmeister W (eds). Singapore, pp. 173-192.

78. Chan HM (2004) Sharing death and dying: advance directives, autonomy and the family. Bioethics 18(2): 87-103.

79. Suratman S (2011) Studies on Malay Families and Households in Singapore - A critical Assessment. National University of Singapore, Singapore.

80. Chua BH (1998) Culture, multiracialism and national identity in Singapore in Trajectories: Inter Asia Cultural Studies. Chen KH (ed). Routledge, USA, pp. 186-205.

81. Clammer J (1985) Ethnicity and the Classification of Social Differences 
in Plural Societies. Journal of Asian and African Studies 20(3-4): 141155.

82. Low JA, Ng WC, Yap KB, Chan KM (2000) End-of-life issues- preferences and choices of a group of elderly Chinese subjects attending a day care centre in Singapore. Ann Acad Med Singapore 29(1): 50-56.

83.Toh HC (2011) Providing hope in terminal cancer: When is it appropriate and when is not? Ann Acad Med Singapore 40(1): 50-55.

84. Tan TK, Teo FC, Wong K, Lim HL (1993) Cancer: To tell or not to tell? Singapore Med J 34(3):202-203.

85. Krishna L (2011) Nasogastric feeding at the end of life: A virtue ethics approach. Nurs Ethics 18(4): 485-494.

86. Black J (2011) What are patients' priorities when facing the end of life? A critical review. Int J Palliat Nurs 17(6): 294-300.

87.http://east.merriam-webster.com/dictionary/familism

88. http://family.jrank.org/pages/859/India-Family-Life-Family-Values. html

89. Ho ZJM, Krishna LKR, Goh C, Yee CPA (2013) The physician-patient relationship in treatment decision making at the end of life: A pilot study of cancer patients in a Southeast Asian society. Palliative and Supportive Care 11(1): 13-19.

90. Stivens M (2006) 'Family values' and Islamic revival: Gender, rights and state moral projects in Malaysia. Women's Studies International Forum 29(4): 354-367.

91. Yang GM, Kwee AK, Krishna L (2012) Should patients and family be involved in "Do not resuscitate" decisions? Views of oncology and palliative care doctors and nurses. Indian J Palliat Care 18(1): 52-58.

92. Foo WT, Zheng Y, Yang GM, Kwee AK, Krishna L (2013) Factors considered in end of life decision making of health care professional. Am J Hosp Palliat Med 30(4): 354-358.

93.http://www.ncl.ac.uk/ecls/assets/documents/pdf/countryfiles/ CCC-Singapore.pdf

94. Englehart NA (2000) Rights and culture in the Asian values argument the rise and fall of confucian ethics in Singapore. Human Rights Quarterly, 22(2): 548-568.

95. Chong JA, Quah YL, Yang GM, Menon S, Radha Krishna LK (2013) Patient and family involvement in decision making for management of cancer patients at a centre in Singapore. BMJ Support Palliat Care doi:10.1136/bmjspcare-2012-000323.

96. Chai HZ, Radha Krishna LK, Wong VH (2013) Feeding: What it means to patients and caregivers and how these views influence Singaporean Chinese Caregivers' decisions to continue feeding at the end of life. Am J Hosp Palliat Care DOI: 10.1177/1049909113480883.

97. Chan CK, Yau MK (2009) Death preparation among the ethnic Chinese well-elderly in Singapore: an exploratory study. Omega 60(3): 225239.

98. Pang MC (1999) Protective truthfulness: the Chinese way of safeguarding patients in informed treatment decisions. J Med Ethics 25(3): 247-253.

99. Tse CY, Chong A, Fok SY (2003) Breaking bad news: a Chinese perspective. Palliat Med 17(4): 339-343.

100. Chuang YC (2005) Effects of interaction pattern on family harmony and well being; Test of interpersonal theory, relational models and Confucian ethics. Asian J Social Psychology 8(3): 272-291.
101. Koh EK, Koh CK (2008) Caring for older adults: the parables in Confucian texts. Nurs Sci Q 21(4): 365-368.

102. Guo Z (1995) Chinese Confucian culture and medical ethical tradition. J Med Ethics 21(4): 239-246.

103. Tang ST (2000) Meanings of dying at home for Chinese patients in Taiwan with terminal cancer: A literature review. Cancer Nurs 23(5): $367-70$

104. Holroyd E (2003) Hong Kong Chinese Family Caregiving: Cultural Categories of Bodily Order and the Location of Self. Qual Health Res 13(2): 158-170

105. Ang A, Loke PC, Campbell AV, Chong SA (2009) Live or let die: ethical issues in a psychiatric patient with end stage renal failure. Ann Acad Med Singapore 38(4): 370-374.

106. Cong Y (2004) Doctor-family-patient relationship: the Chinese paradigm of informed consent. J Med Philos 29(2): 149-178.

107. Lee SK (2009) East Asian attitudes toward death - a search to help East Asian elderly dying in contemporary America. Perm J 13(3): 5560.

108. Fan R (2007) Which care? Whose Responsibility? And why Family? A Confucian account of long term care of the elderly. J Med Philos 32(5): 495-517.

109. Cheng SK (1990) Understanding the culture and behavior of East Asians--a Confucian perspective. Australian N Z J Psychiatry 24(4): 510-515.

110. Tao LPW (2007) Dignity in long term care for older people. J Medicine and Philosophy 32(5): 465-481.

111. Lu L, Yu YL (1998) Family roles and happiness in adulthood. Personality and Individual Differences 25(2): 195-207.

112. Lo PC (1999) Confucian ethic of death with dignity and its contemporary relevance. Annu Soc Christ Ethics 19: 313-33.

113. Htut Y, Shahrul K, Poi PJ (2007) The views of older Malaysians on advanced directive and advanced care planning: a qualitative study. Asia Pac J Public Health 19(3): 58-67.

114. Low JA, Ng WC, Yap KB, Chan KM (2000) End-of-life issues-preferences and choices of a group of elderly Chinese subjects attending a day care centre in Singapore. Ann Acad Med Singapore 29(1): 50-56.

115. Tang ST, Liu TW, Lai MS, Liu LN, Chen CH (2005) Concordance of preferences for end-of-life care between terminally Ill cancer patients and their family caregivers in Taiwan. J Pain Symptom Manage 30(6): 510-518.

116. Tai MC, Lin CS (2001) Developing a culturally relevant bioethics for Asian people. J Med Ethics 27(1): 51-54.

117. Nichols L, Prescott N, Phua KH (1997) Medical savings accounts for developing countries. Innovations in Health Care Financing, World Bank Group.

118. Hanvoranavongchai P (2002) Medical Savings Accounts: Lessons Learned from International Experience. World Health Organization.

119. Taylor R, Blair S (2003) Financing Health Care: Singapore's Innovative Approach. Public Policy for the Private Sector, World Bank Group.

120. Hsiao WC (1995) Medical savings accounts: lessons from Singapore. Health Aff 14(2): 260-269. 
121. Lim MK (2002) Singapore's medical savings accounts--beyond rhetoric and doctrine to "what works": a response from Singapore. J Health Polit Policy Law 27(2): 302-304.

122. Barr MD (2001) Medical savings accounts in Singapore: a critical inquiry. J Health Polit Policy Law 26(4): 709-726.

123. Whitehead M (2000) The concepts and principles of equity and health. World Health Organization Regional Office for Europe, Denmark.

124. Lim MK (2004) Shifting the burden of health care finance: a case study of public-private partnership in Singapore. Health Policy 69(1): 83-92.

125. Healthcare Financing, Singapore Health Care System, Ministry of Health Singapore.

126. Maintenance of Parent Act 2010.

127. http://www.geraldtan.com/medaffairs/hota.html

128. http://forum.singaporeexpats.com/ftopic40185.html?t=40\%20185

129. Voo TC, Campbell AV, De Castro LD (2009) The ethics of organ transplantation: shortages and strategies. Ann Acad Med Singapore 38(4): 359-364.
130. Brain-dead man's kin in scuffle over op to remove organs (2007) Tracy Sia in Straits Times 8.

131. Verpoort C, Gastmans C, De Bal N, Dierckx de Casterlé B (2004) Nurses' Attitudes to Euthanasia: a review of the literature. Nurs Ethics 11(4): 349-365.

132. Berghs M, Dierckx de Casterlé B, Gastmans C (2005) The complexity of nurses' attitudes toward euthanasia: a review of the literature. J Med Ethics 31(8): 441-446.

133. Seale C (2009) Hastening death in end-of-life care: a survey of doctors. Soc Sci Med 69(11): 1659-1666.

134. Ryan CJ (1998) Pulling up the runaway: the effect of new evidence on euthanasia's slippery slope. J Med Ethics 24(5): 341-344

135. Gordijn B, Janssens R (2000) The prevention of euthanasia through palliative care: New developments in The Netherlands. Patient Educ Couns 41(1): 35-46.

136. Leichtentritt RD, Rettig KD, Miles SH (1999) Holocaust survivors' perspectives on the euthanasia debate. Soc Sci Med 48(2): 185-196. 